Mayorga, A. and A. Contreras-Ramos. 2017. The new species Anacroneuria brava (Plecoptera: Perlidae), with provisional description of an unassociated female, and new distribution records from Mexico. Illiesia, 13(02):23-29. https://doi.org/10.25031/2017/13.02

http://zoobank.org/ urn:Isid:zoobank.org:pub:D121E665-B015-4659-8E28-21B8FA79303D

\title{
THE NEW SPECIES ANACRONEURIA BRAVA (PLECOPTERA: PERLIDAE), WITH PROVISIONAL DESCRIPTION OF AN UNASSOCIATED FEMALE, AND NEW DISTRIBUTION RECORDS FROM MEXICO
}

\author{
Alfredo Mayorga ${ }^{1}$ and Atilano Contreras-Ramos ${ }^{1}$ \\ ${ }^{1}$ Instituto de Biología, UNAM, Depto. de Zoología, Colección Nacional de Insectos (CNIN), \\ 04510 Mexico City, Mexico. \\ Corresponding author: Alfredo Mayorga E-mail: amayorga.entomology@gmail.com)
}

\begin{abstract}
Anacroneuria brava Mayorga \& Contreras-Ramos, 2017 (Plecoptera: Perlidae) is described as new from Estado de Mexico. A second species, Anacroneuria sp. MX-1, is provisionally described from a single female from the state of Oaxaca. The distribution of the Anacroneuria species known from Mexico is updated and the first stonefly records for the states provided for Hidalgo and Querétaro. Moreover, new distribution records are provided for A. annulicauda (Pictet, 1841), A. lineata (Navás, 1924), A. nigrolineata Jewett, 1958, A. planicollis Klapálek, 1923 and A. quadriloba Jewett, 1958.
\end{abstract}

Keywords: Anacroneuria brava Mayorga \& Contreras-Ramos, 2017, Plecoptera, Perlidae, Mexico, Estado de México, Oaxaca, stoneflies.

\section{INTRODUCTION}

The Anacroneuria from Mexico are better known from the states of the south than elsewhere. Currently, the Mexican states with the greatest number of recorded Anacroneuria species are Chiapas, Veracruz, and Oaxaca, with 16, 10, and 14 species, respectively. Heretofore, just 18 of the 32 Mexican states (56\%) have records of Anacroneuria species. Therefore, there is great potential to increase the known species richness in many states in Mexico (Mayorga 2016, Gutiérrez-Fonseca 2009, Stark \& Kondratieff 2004).

In this work, we describe $A$. brava, sp. nov. from
Estado de México, and provisionally describe Anacroneuria sp. MX-1 from Oaxaca. Moreover, new records for $A$. annulicauda (Pictet, 1841), A. lineata (Navás, 1924), A. nigrolineata Jewett, 1958, A. planicollis Klapálek, 1923, and A. quadriloba Jewett, 1958 are presented. The known distribution of Anacroneuria species in Mexico is updated with first time records for the states of Hidalgo and Querétaro.

\section{MATERIALS AND METHODS}

The holotype and all other specimens examined for this study are stored in $80 \% \mathrm{EtOH}$ in the 

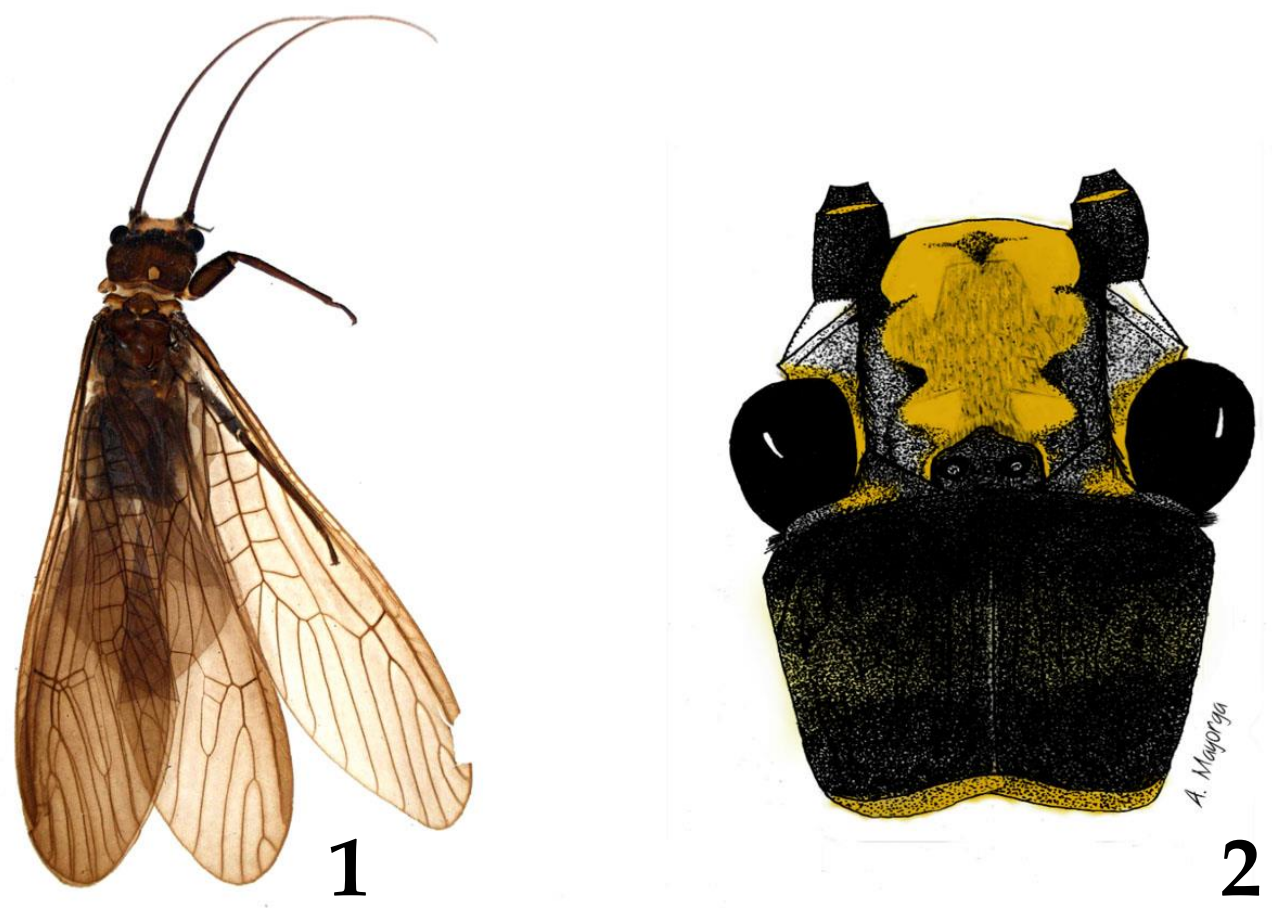

Figs. 1-2. Anacroneuria brava sp. nov. 1. Adult habitus. 2. Male head and pronotum.

Colección Nacional de Insectos (CNIN), Instituto de Biología, Universidad Nacional Autónoma de México (UNAM), Mexico City. Terminalia were clipped and cleared in $10 \% \mathrm{KOH}$ using the procedures of Stark \& Zúñiga (2003). An American Optical Company stereomicroscope was used to examine the specimens. Illustrations were hand drawn. Photographs of specimens were taken with an Auto-Montage system attached to a Zeiss Axio Zoom V16 stereomicroscope. Editing of the images was conducted using "Ipiccy", a free, online photo editor (http://ipiccy.com/).

\section{RESULTS AND DISCUSSION}

Anacroneuria brava Mayorga \& Contreras-Ramos, sp. nov.

http://lsid.speciesfile.org/urn:lsid:Plecoptera.speciesfile.org: TaxonName:497668

(Figs. 1-5)

Material Examined. Holotype $\hat{\sigma}$ (CNIN-PLH-3): MEXICO: Estado de México, Valle de Bravo,
[19.19512, -100.13261, post-processed to $10 \mathrm{~km}$ radius; mean elevation $1800 \mathrm{~m}$ a.s.l.], July 1979, J. Bueno.

Adult habitus. General color of body dark (Fig. 1). Head pigmentation with complex pattern. Pigment pattern over ocelli pentagonal-shaped and black tinted; a truncated arrow-shaped pattern defined by short, fine setae replaces usual M-line; a dark, diamond-shaped area centered on clypeus; lappets obscure and elongate; mesal area of head well defined and sclerotized; anterior to ocelli a zig-zag pattern extends to bases of antennae; circumantennal ridges connect lappets by dark shading to anterior margin of eyes; white rhomboidal-shaped plate located above the ridges; dark triangles with middle inclined brown band at posterior area of eyes. Pronotum with narrow, brown mid longitudinal stripe; discs dark with scattered rugosities obscured; a paler, wide transverse band (Fig. 2). Wing membrane dark brown with veins darker (Fig. 1). Fore leg completely dark brown, with subtle dark stripe at proximal end of femur. 
Mayorga, A. and A. Contreras-Ramos. 2017. The new species Anacroneuria brava (Plecoptera: Perlidae), with provisional description of an unassociated female, and new records of distribution from Mexico. Illiesia, 13(02):23-29. https://10.25031/2017/13.02

Male. Forewing length $20 \mathrm{~mm}$. Hammer absent. Ventral: Aedeagal apex truncate and straight, little constricted at base; aedeagus arms slightly widened and curved subapically bearing a pair of small membranous lobes at center. Hooks slender, typical in appearance; space between hooks forming an antique door lock-shape; interior corners from the base of hooks sclerotized with a small bulge on both sides at vertex; frontal walls of mesal area with some bristles on each side (Fig. 3). Dorsal: Simple. Aedeagal keel consists of a lengthened projection with straight margins laterally, circular anteriorly and triangular posteriorly, poorly sclerotized and transparent (Fig. 5).

Female. Unknown.

Larva. Unknown.

Distribution. Mexico, Estado de México, Valle de Bravo.

Diagnosis. This species is similar to A. aethiops (Walker, 1852), A. brailovskyi Stark \& Kondratieff,
2004, A. flavifacies Jewett, 1958 and A. ratcliffei Stark \& Kondratieff, 2004 in pronotal pigment pattern, however that of $A$. brava is far more complex (Fig. 2). The body size of $A$. brava is also larger than $A$. aethiops, $A$. braivloskyi and $A$. flavifacies. The aedeagus of $A$. brava is similar to $A$. brailovskyi but its apex is truncate, while in A. brailovskyi it is concave. The shape of the dorsal, transparent keel (Figs. 3, 5), clearly distinguishes this one from all other Anacroneuria species.

Comments. This is one of the largest and darkest species of Mexican Anacroneuria (Fig. 1). The specimen was found pinned on the pronotum, and was unpinned and transferred to $\mathrm{EtOH}$; body coloration, pigment patterns, and diagnostic structures are well preserved.

Etymology. The species name, used as a noun in apposition, is based to the type locality of "Valle de Bravo".
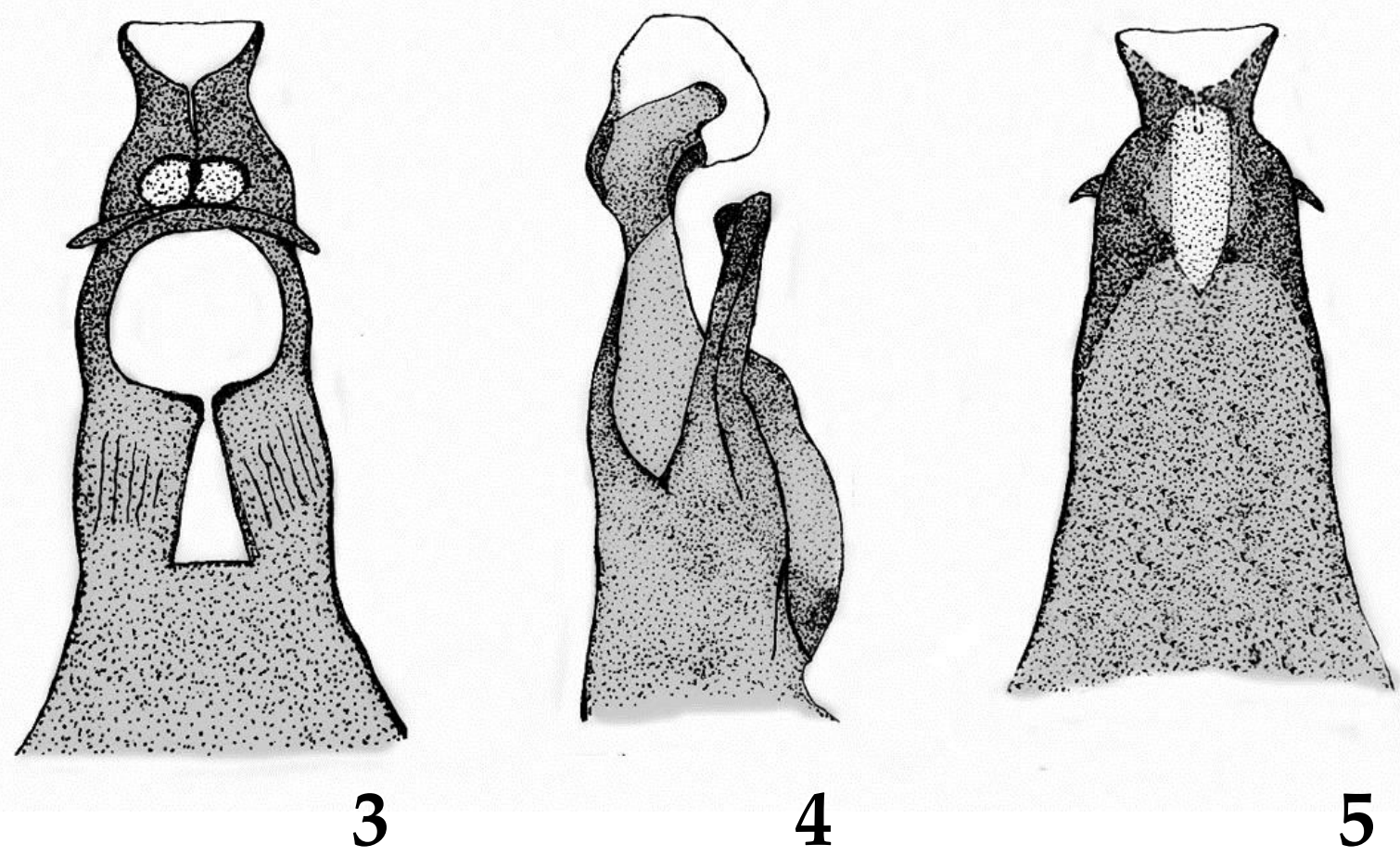

Figs. 3-5. Anacroneuria brava sp. nov. 3. Aedeagus, ventral. 4. Aedeagus, lateral. 5. Aedeagus, dorsal.

\section{Anacroneuria sp. MX-1}

(Figs. 6-8)
Material examined. MEXICO: Oaxaca, Mpio. 
Mayorga, A. and A. Contreras-Ramos. 2017. The new species Anacroneuria brava (Plecoptera: Perlidae), with provisional description of an unassociated female, and new records of distribution from Mexico. Illiesia, 13(02):23-29. https://10.25031/2017/13.02

Santiago Comaltepec, Sierra Juárez, Localidad “La Esperanza", 17³8'28.20" N, 96²2'02.81" W, 6 May 2016, $1750 \mathrm{~m}$ a.s.1., A. Mayorga, R. Turrent, 1 우 (CNIN-PLH-4).

Adult habitus. General body color yellow and dark brown. Head pale yellow, locally hirsute. Pigment pattern over ocelli and M-line defined by short setae; a lightly pigmented T-shaped area extends from compound eyes medially and caudally toward occiput; a well-defined, basal transverse line posterior to ocelli; a wide, curved V-shaped pattern extends onto clypeus; lappets dark brown with long vertical rows of thick setae extending from foot of lappets to anteromedial corners of compound eyes; circumantennal ridges connect lappets to anterior margin of eyes, forming a right triangle; white rhomboid-shaped plate present anterior to ridges; darkened area posterolateral to compound eyes formed by long, stout setae. Pronotum with narrow medial band; mediolateral pale bands wide and setose centrally; lateral discs dark brown with slightly lighter rugose areas; russetted areas laterally occupy length of pronotum. Antennae dark, scape in dorsal view with discrete yellow, basal rugosity. Wing membranes brown, veins darker. Fore legs mostly pale, femur distally ringed with dark pigment extending medially on dorsal surface. Tibia dark at basal and distal rings, these usually connected dorsally.

Male. Unknown.

Female. Forewing length $20 \mathrm{~mm}$. Subgenital plate 4lobed; lobes connected by a white membrane; inner lobes shorter than wide, posterior margins obscure and truncate, separated by a wide, shallow, Vshaped notch, margins well sclerotized. Outer lobes narrow and square posteriorly, margins wellsclerotized; a narrow, V-shaped notch separating outer and inner lobes. A large, V-shaped bulge present anterior to median notch, bulge covered with scattered bristles. Mesal field of sternum 9 with dispersed fine setae, anterior margin closely follows subgenital plate lobes; posterolateral margins of segment darkly pigmented.

Larva. Unknown.
Distribution. Mexico, Oaxaca, Sierra Juárez, La Esperanza.

Diagnosis. This species differs from other Mesoamerican Anacroneuria species because of the complexity of the subgenital plate, the densely setose areas around the lappets, and a unique pigmentation of the head.

Comments. This species was the only stonefly that came to our light trap the day we collected at La Esperanza, Oaxaca. This location was about $1 \mathrm{~km}$ from the nearest stream source, supporting that species in the genus are capable of moderate dispersal. A pinned, similarly pigmented, female specimen was found in the CNIN from Oaxaca, 1955. Unfortunately, its poor condition negated positive identification. We hope to discover additional specimens, including males, and formally describe this species.

Anacroneuria annulicauda (Pictet, 1941)

http://lsid.speciesfile.org/urn:lsid:Plecoptera.speciesfile.org: TaxonName:1983

Material Examined. MEXICO: Puebla, Mpio. Zihuateutla, Barranca de Patla, Río Necaxa, $20^{\circ} 15^{\prime} 11.33^{\prime \prime} \mathrm{N}, 97^{\circ} 52^{\prime} 02.47^{\prime \prime} \mathrm{W}, 6$ September 2015, $481 \mathrm{~m}$ a.s.l, Rafael Turrent, 19; same data and collector, 17-18 June 2016, 3; Puebla, Mpio. Hueytamalco, Rancho "La Carolina”, E Ayotoxco, 30 m a.s.l., April 1989, F. López, 1 ㅇ․

Comments. This species was previously reported for the states of Chiapas, Guerrero, Nayarit, Oaxaca, Sonora, and Veracruz (Stark \& Kondratieff 2004, Mayorga 2016). This is the first record of this species from Puebla.

Anacroneuria lineata (Navás, 1924)

http://lsid.speciesfile.org/urn:lsid:Plecoptera.speciesfile.org: TaxonName:2026

Material Examined. MEXICO: Puebla, Metlac, 17 February 1977, J. Bueno, 3 ${ }^{\lambda}$; Querétaro, Km 8 Neblinas Agua-Zarca, 21 July 1998, 2115'14” N, $99^{\circ} 04^{\prime} 58^{\prime \prime}$ W, E. Barrera, C. Mayorga, 1 ㅇ. 
Mayorga, A. and A. Contreras-Ramos. 2017. The new species Anacroneuria brava (Plecoptera: Perlidae), with provisional description of an unassociated female, and new records of distribution from Mexico. Illiesia, 13(02):23-29. https://10.25031/2017/13.02
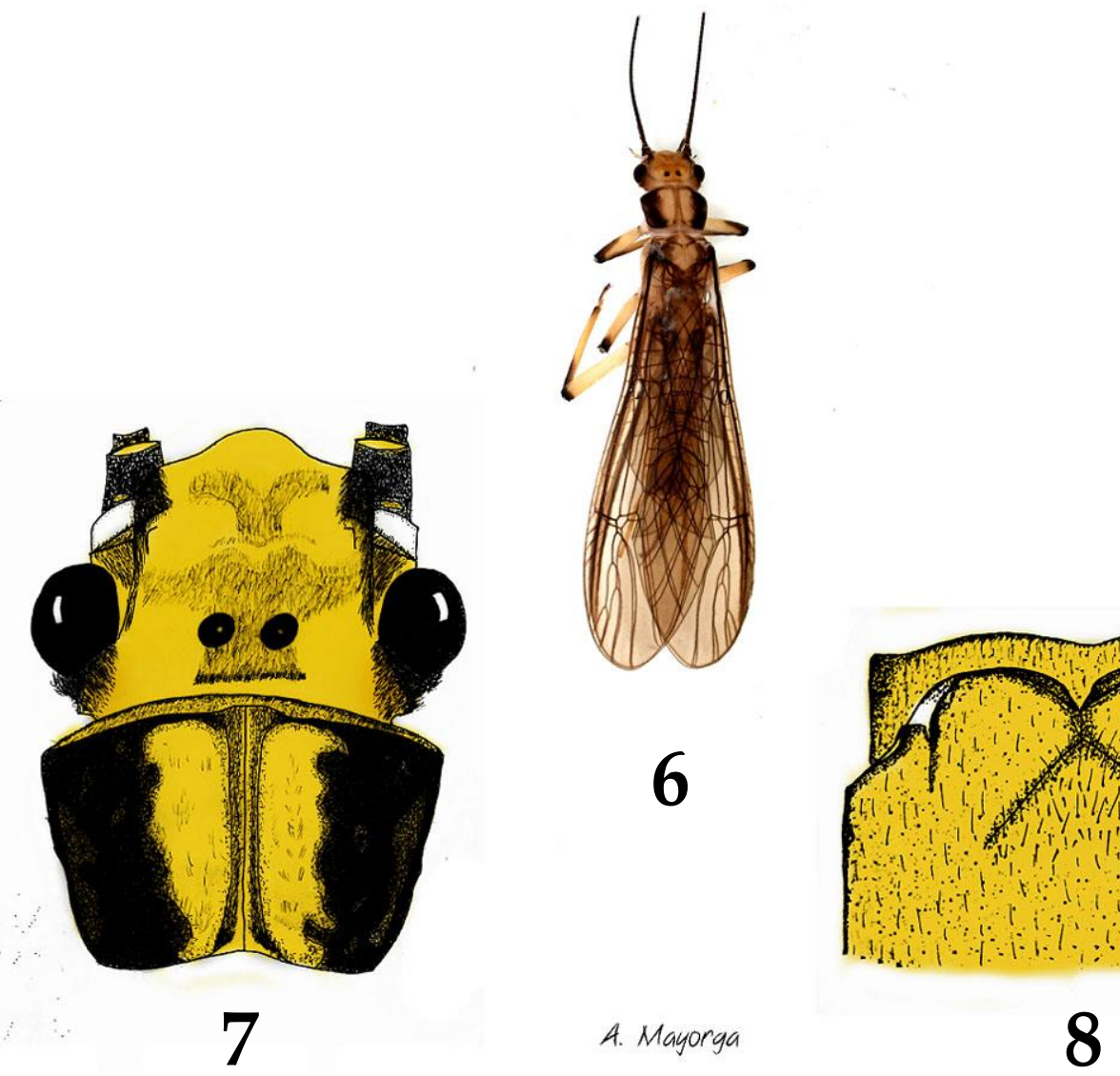

Figs. 6-8. Anacroneuria sp. MX-1. 6. Adult habitus. 7. Female head and pronotum. 8. Subgenital plate.

Comments. This Anacroneuria species has one of the widest distributions in Mexico (Stark \& Kondratieff 2004). We present the first records of this species for both Puebla and Querétaro states.

Anacroneuria nigrolineata Jewett, 1958 http://lsid.speciesfile.org/urn:lsid:Plecoptera.speciesfile.org: TaxonName:1818

Material Examined. MEXICO: Querétaro, km 8 Neblinas Agua-Zarca, 21 July1998, 21 ${ }^{\circ} 15^{\prime} 14^{\prime \prime}$ N, $99^{\circ} 04^{\prime} 58^{\prime \prime}$ W, E. Barrera, C. Mayorga, $1 \delta^{\lambda}$.

Comments. We present the first ever record for this species in Querétaro state. Previously, the species was reported from Guerrero and Sonora (Stark \& Kondratieff 2004).

Anacroneuria planicollis Klapálek, 1923 http://lsid.speciesfile.org/urn:lsid:Plecoptera.speciesfile.org: TaxonName: 1784

Material Examined. MEXICO: Hidalgo, Huasca,
Rancho Sta. Elena, Manantial de las Vigas, $20^{\circ} 07^{\prime} 52.2^{\prime \prime} \mathrm{N}, 98^{\circ} 31^{\prime} 39.0^{\prime \prime} \mathrm{W}, 2480 \mathrm{~m}$ a.s.1. 21-03 May 2005, A. Contreras-Ramos, E. Meléndez, Malaise trap, $1 \delta^{\lambda}, 1$ ㅇ.

Comments. The specimens of this species were collected together with A. quadriloba. A. planicollis is another widely distributed species in Mexico. We present the first state record from Hidalgo.

\section{Anacroneuria quadriloba Jewett, 1958}

http://lsid.speciesfile.org/urn:lsid:Plecoptera.speciesfile.org: TaxonName:1771

Material Examined. Mexico: Hidalgo, Huasca, Rancho Sta. Elena, Manantial de las Vigas, $20^{\circ} 07^{\prime} 52.2^{\prime \prime} \mathrm{N}, 98^{\circ} 31^{\prime} 39.0^{\prime \prime} \mathrm{W}, 2480 \mathrm{~m}$ a.s.1. 21-03 May 2005, A. Contreras-Ramos, E. Meléndez, Malaise trap, 3̂̉, 1 ; Puebla, Ahuatlán, 1200 m a.s.l., 18 March 1987, H. Brailovsky, 1 q . 
Mayorga, A. and A. Contreras-Ramos. 2017. The new species Anacroneuria brava (Plecoptera: Perlidae), with provisional description of an unassociated female, and new records of distribution from Mexico. Illiesia, 13(02):23-29. https://10.25031/2017/13.02

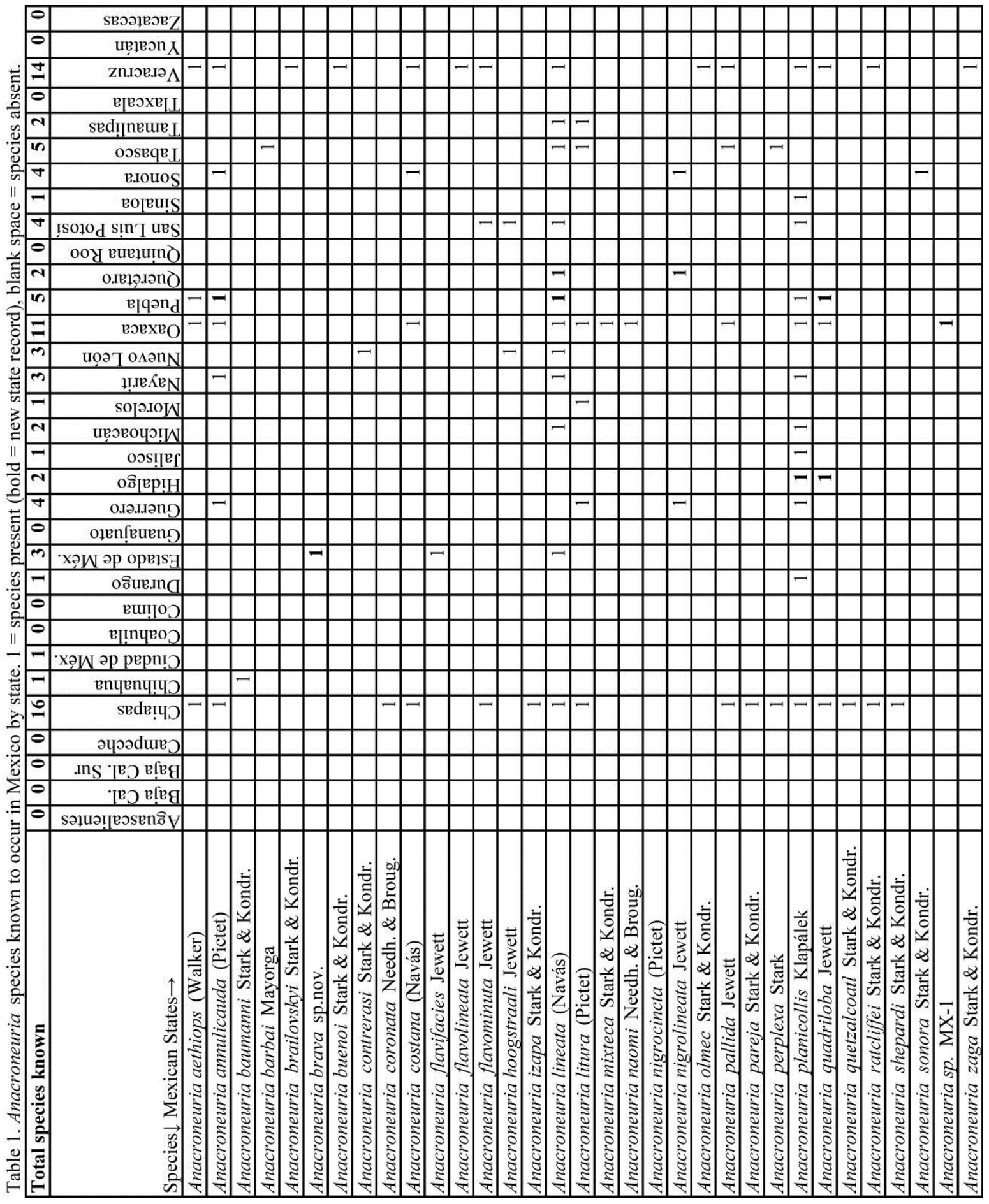

Table 1. Anacroneuria species known to occur in Mexico by state. $1=$ species present $(b o l d=$ new state record), blank space $=$ species absent. 
Mayorga, A. and A. Contreras-Ramos. 2017. The new species Anacroneuria brava (Plecoptera: Perlidae), with provisional description of an unassociated female, and new records of distribution from Mexico. Illiesia, 13(02):23-29. https://10.25031/2017/13.02

Comments. This species was previously reported from Chiapas, Oaxaca, and Veracruz. These are the first records for Hidalgo and Puebla.

\section{CONCLUSIONS}

The description of A. brava sp. nov. brings the number of Anacroneuria species known from Mexico to 32 . The number of states with specimen records for this genus increases to $20(62 \%)$ (Table 1). This paper reports seven new state records, with first ever records for Anacroneuria in the states of Hidalgo and Querétaro. With concerted effort, most states will eventually be shown to support one or more species of Anacroneuria. In addition, 19 of the $32(59 \%)$ species are exclusively present in Mexico (Stark \& Kondratieff 2004, Mayorga 2016), this highlights the importance of the group within the aquatic insect diversity from this country.

\section{ACKNOWLEDGEMENTS}

We thank the aquatic entomologist Rafael BarbaAlvarez from IBUNAM for his support and advice in the laboratory. We also thank Cristina Mayorga (IBUNAM) for granting access to the collection. We thank lepidopterist Rafael Turrent we thank his invitation to join his field work in Oaxaca, and to the community of "La Esperanza" for facilitating access to the area. Thanks to biologist Susana Guzmán Gómez (IBUNAM) who provided advice on using the Auto-Montage system. Special thanks to Dr. Edward DeWalt (University of Illinois) and an anonymous reviewer for their useful observations that improved this work.

\section{REFERENCES}

Gutiérrez-Fonseca, P.E. 2009. Ecología, reproducción, taxonomía y distribución de Anacroneuria spp. Klapálek 1909 (Insecta: Plecoptera: Perlidae) en Costa Rica. Bachelor's degree thesis, San José, Costa Rica: Universidad de Costa Rica, Facultad de Ciencias, Escuela de Biología. 69 pp.

Mayorga, A. 2016. A new species of Anacroneuria Klapálek (Plecoptera: Perlidae) and complementary descriptions of three additional species from Mexico, with comments on the current knowledge of Mexican species of the genus. Illiesia, 12:64-73.

Stark, B.P. \& B.C. Kondratieff. 2004. Anacroneuria from Mexico and upper Mesoamerica (Plecoptera: Perlidae). Monographs of the Western North American Naturalist, 2:1-64.

Stark, B.P. \& M.C. Zúñiga. 2003. The Anacroneuria guambiana complex of South America (Plecoptera: Perlidae). Pages 229-237. In: Gaino, E. [editor]. Research Update on Ephemeroptera and Plecoptera. University of Perugia, Perugia.

Submitted 16 March 2017, Accepted 6 July 2017, Published 21 July 2017

Hosted and published at the University of Illinois, Illinois Natural History Survey, Champaign, Illinois, U.S.A. 